https://helda.helsinki.fi

\title{
3D-printability of aqueous poly(ethylene oxide) gels
}

\section{Viidik, Laura}

2019-11

Viidik , L , Seera , D , Antikainen , O , Kogermann , K, Heinämäki , J \& Laidmäe , I 2019 , ' 3D-printability of aqueous poly(ethylene oxide) gels ' , European Polymer Journal , vol. 120 , 109206 . https://doi.org/10.1016/j.eurpolymj.2019.08.033

http://hdl.handle.net/10138/333395

https://doi.org/10.1016/j.eurpolymj.2019.08.033

cc_by_nc_nd

acceptedVersion

Downloaded from Helda, University of Helsinki institutional repository.

This is an electronic reprint of the original article.

This reprint may differ from the original in pagination and typographic detail.

Please cite the original version. 


\section{Journal Pre-proofs}

3D-printability of aqueous poly(ethylene oxide) gels

Laura Viidik, Dagmar Seera, Osmo Antikainen, Karin Kogermann, Jyrki

Heinämäki, Ivo Laidmäe

PII:

S0014-3057(19)31002-X

DOI:

https://doi.org/10.1016/j.eurpolymj.2019.08.033

Reference:

EPJ 9206

To appear in:

European Polymer Journal

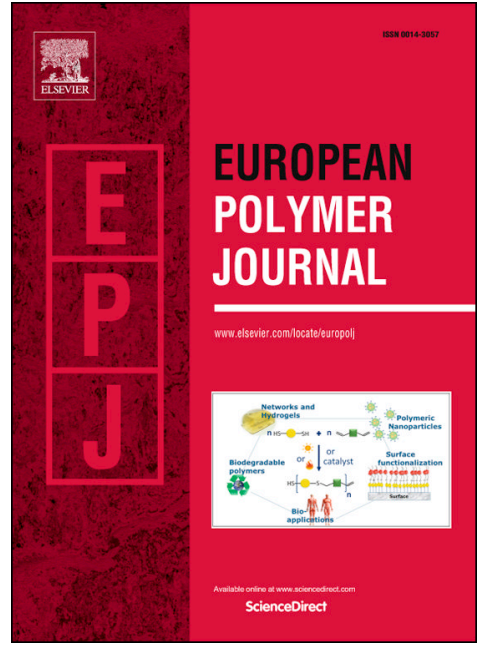

Received Date: $\quad 18$ May 2019

Revised Date: $\quad 20$ August 2019

Accepted Date: $\quad 22$ August 2019

Please cite this article as: Viidik, L., Seera, D., Antikainen, O., Kogermann, K., Heinämäki, J., Laidmäe, I., 3Dprintability of aqueous poly(ethylene oxide) gels, European Polymer Journal (2019), doi: https://doi.org/10.1016/ j.eurpolymj.2019.08.033

This is a PDF file of an article that has undergone enhancements after acceptance, such as the addition of a cover page and metadata, and formatting for readability, but it is not yet the definitive version of record. This version will undergo additional copyediting, typesetting and review before it is published in its final form, but we are providing this version to give early visibility of the article. Please note that, during the production process, errors may be discovered which could affect the content, and all legal disclaimers that apply to the journal pertain.

(C) 2019 Published by Elsevier Ltd. 


\section{D-printability of aqueous poly(ethylene oxide) gels}

Laura Viidik $^{\mathrm{a},{ }^{*}, \text { Dagmar Seera }^{\mathrm{a}} \text {, Osmo Antikainen }}{ }^{\mathrm{b}}$, Karin Kogermann ${ }^{\mathrm{a}}$, Jyrki Heinämäki ${ }^{\mathrm{a}}$, Ivo Laidmäe $e^{a, c}$

${ }^{a}$ Institute of Pharmacy, Faculty of Medicine, University of Tartu, Nooruse 1, 50411 Tartu, Estonia

${ }^{\mathrm{b}}$ Division of Pharmaceutical Chemistry and Technology, Faculty of Pharmacy, Viikinkaari 5E, 00014 University of Helsinki, Finland

${ }^{c}$ Department of Immunology, Institute of Biomedicine and Translational Medicine, Faculty of Medicine, University of Tartu, Ravila 19, 50411 Tartu, Estonia

Corresponding Author: Laura Viidik*

Mailing address: Institute of Pharmacy, University of Tartu, Nooruse 1, 50411 Tartu, Estonia Tel.: +37256 609319

E-mail: laura.viidik@ut.ee 


\section{Abstract}

Printing technologies combined with a computer-aided design (CAD) have found an increasing number of uses in pharmaceutical applications. In extrusion-based printing, the material is forced through a nozzle to form a three-dimensional (3D) structure pre-designed by CAD. The aim of this study was to evaluate the 3D-printability of biocompatible aqueous poly(ethylene oxide) (PEO) gels and to investigate the effects of thee formulation parameters on the 3D printing process. The impact of PEO concentration (gel viscosity), printing head speed and printing plate temperature was investigated at three different levels using a full factorial experimental design. The aqueous PEO gels were printed with a bench-top extrusion-based 3D printing system at an ambient room temperature. The viscosity measurements confirmed that the aqueous PEO gels follow a shear-thinning behaviour suitable for extrusion-based printing. Heating the printing plate allowed the gel to dry faster resulting in more precise printing outcome. With the non-heated plate, the gel formed a dumbbell-shaped grid instead of straight lines. Higher concentration and more viscous PEO gels formed the best structured 3D-printed lattices. In conclusion, the accuracy and precision of extrusion-based 3D printing of aqueous PEO gels is highly dependent on the formulation (PEO concentration) and printing parameters (printing head speed, plate temperature). By optimizing these critical process parameters, PEO may be suitable for printing novel drug delivery systems.

Keywords: Extrusion-based 3D printing; Poly(ethylene oxide); Gel; Viscosity; Process parameters; Drug delivery system 


\section{Introduction}

Three-dimensional (3D) printing is a technique for layer-by-layer creation of pre-designed 3D structures of any shape. Today, there are a lot of different 3D printing methods available using either powders, liquids or semisolids as initial material. Extrusion-based 3D printing forms the designed structures and shapes by forcing given material directly through a nozzle. Extrusionbased 3D printing combined with a computer-aided design (CAD) has been used for different applications, e.g. in tissue engineering, drug delivery systems (DDSs) and food printing. The carrier material used for the extrusion-based printing is commonly in a semisolid or molten state. More recently, an increasing interest in using hydrogels as an alternative carrier material in extrusion-based 3D printing is being reported in the literature [1-4]. Hydrogels are widely used for extrusion-based 3D printing applications, mostly due to their suitability to be used for tissue engineering or organ biopriating (e.g. degradation, biological response, compatibility) $[1,2,4]$. The latter is also related with the selection of suitable polymers and good 3D printing properties of hydrogels enabling more precise control of deposition.

While 3D printing is extensively used and is considered as a promising future fabrication method for food products and pharmaceuticals, a number of challenges still need to be overcome. These include e.g., finding well-printable biocompatible materials, improving the performance of the printing systems, gaining understanding of the $3 \mathrm{D}$ printing process, and optimization of the process [5]. The well-known "bottle neck" for the use of 3D printing in medical applications is to find suitable biocompatible polymers as carrier materials [6,7]. Materials used in medical and pharmaceutical applications need to be biocompatible, biodegradable and non-toxic. Moreover, the materials need to comply with the technical requirements set by the printing technology used. Therefore, the chemical and physical properties of the carrier materials are of vital importance $[8,9]$. When printing with semisolid 
materials such as gels, pastes, viscosity is one of the key parameters, and thus the rheological tests are critical for assessing the suitability of any material for printing [10-13]. The material needs to be viscous enough to maintain structural integrity after printing. With the materials being too viscous, higher force is needed to inject it through the printer head nozzle. Here a shear thinning behaviour of the material is beneficial. Other material properties affecting printability include the gelation mechanism, surface tension, density, and thermal properties $[4,14]$.

Poly(ethylene oxide) (PEO) is a hydrophilic, thermoplastic semi-crystalline synthetic polymer obtained by the polymerization of ethylene oxide monomer [15]. PEO is biocompatible and biodegradable, thus making it a suitable material for pharmaceutical and biomedical applications either on its own, in the composition of copolymers or in combination with other polymers. PEO has been used in the $3 \mathrm{D}$ printing of composite materials. For example, Pluronic ${ }^{\circledR}$ block-copolymer (consisting of PEO - polypropylene oxide - PEO) allows the 3D printing of vascularized tissue constructs [16]. PEO has also been used as the viscosity enhancer for printing polyurethane elastomers [17]. Beside PEO other pharmaceutically relevant polymers are studied for extrusion-based printing. These include e.g. hydroxypropyl cellulose [18], hydroxypropyl methylcellulose, microcrystalline cellulose $[19,20]$ and polyvinyl alcohol [21]. The range of materials becomes wider when also other printing methods (e.g. powder solidification, selective laser sintering etc.) are considered (reviewed in [22]).

Printability is defined here as the capability of a 3D printer to reproduce a given model created by CAD. This is important because the quality of the final product is determined by the printing process accuracy and precision. To date, only few studies have been published focusing at the evaluation of printability in extrusion-based 3D printing by analysing the final 3D-printed product [10]. This has been performed mainly in two dimensions by taking into 
account either the width of the printed scaffold filament [9,23], filament collapse test [9], overlaps in sharp corner printing [13], area of the lattice gap [13], properties of the lattice gap $[9,24]$, the visual appearance [25] and surface roughness [26] of the 3D printed object.

The 3D printing of pharmaceuticals can be considered as a new chapter in personalized medicine. Since the U. S. Food and Drug Administration (FDA) approved the first 3D printed drug product $\operatorname{Spritam}^{\circledR}$ (an orally disintegrating tablet introduced by Aprecia Pharmaceuticals) in 2015, the applicability of 3D printing of pharmaceuticals has become more and more a topic of discussion [27]. The need for personalised dosage forms, implants and DDSs (personalized release kinetics, multi-active pharmaceutical ingredient (API) dosage forms) is widely discussed and emphasized in relevant literature [20,28-30].

In the development of printed pharmaceuticals, it is of outmost importance to end up in the final product with reproducible dimensions and shape, desired mechanical properties, and controlled drug release. Therefore, understanding of the 3D-printing process, identification of critical process parameters and profound knowledge on the behaviour of printable materials, are crucial. For example, the variations and defects in the geometry and shape of printed DDSs can result in an inadequate drug dosing and delivery [31].

The aim of this study was two-fold: (1) to evaluate the applicability of aqueous PEO gels for an extrusion-based 3D printing and fabricating specially designed platforms (lattices) intended for the development of DDSs; (2) to assess the effects of PEO concentration (gel viscosity) and two process parameters (printing head speed and printing plate temperature) on the printability of PEO and the final geometry and topography of the printed lattices. 


\section{Materials and methods}

\subsection{Materials and gel preparation}

Aqueous gels of poly(ethylene oxide), PEO (MW approx. 900,000, Sigma-Aldrich, USA) were used for extrusion-based 3D-printing. PEO was dissolved approximately for at least 13-15 hours in distilled water at an ambient room temperature to form a viscous gel. The gels were printed as such without further crosslinking. The gels further referred as $10 \%, 15 \%$ and $20 \%$ were prepared dissolving either $1 \mathrm{~g}, 1.5 \mathrm{~g}$ or $2 \mathrm{~g}$ of PEO in $10 \mathrm{ml}$ of distilled water, respectively

\subsection{Lattice design}

The model $5 \times 5$ grid lattice for 3D printing experiments was designed with an Autodesk $^{\circledR}$ 3ds Max $^{\circledR}$ Design 2017 software (Autodesk, Inc., USA). The dimensions for a square-shaped 3D lattice were $20 \times 20 \times 1 \mathrm{~mm}$. The surface area of the theoretical lattice $(\mathbf{1 6 0 . 9}$ $\mathbf{m m}^{\mathbf{2}}$ ) was compared with the experimental areas of the 3D-printed lattices (ranging from $112.5 \mathrm{~mm}^{2}$ to $281.7 \mathrm{~mm}^{2}$ ) via image analysis (as described in 2.5. Evaluation of printability).

\subsection{Viscosity of printing gels}

The viscosity measurements of the gels were conducted with a Physica MCR 101 rheometer (Anton Paar, Austria) using a cone-plate geometry. The measurements were carried out at $25^{\circ} \mathrm{C}$. The viscosity of the gels was measured in a rotational shear test at the controlled shear rates between $100 \mathrm{~s}^{-1}$ to $0 \mathrm{~s}^{-1}$. All measurements were carried out in triplicates.

\section{4. $3 D$ printing}




\section{Joumal Pre-proofs}

The PEO gels were directly printed using a bench-top extrusion-based 3D-printing system (System 30M, Hyrel 3D, USA). The printing head consists of a steel syringe with a plunger that is connected to the stepper motor which moves the plunger up or down and pushes the content in the syringe out. A blunt needle (Gauge, 21G) connected to the syringe serves as a printing nozzle. The printing head (syringe with a nozzle) is mounted to a heating element that allows the control of a temperature inside the syringe during printing (temperature in the printing head). During 3D printing, the printing head is moving at a set speed (printing speed) on $\mathrm{X}-\mathrm{Y}$ axis, extruding the printing material at a specified speed through the nozzle (extrusion speed) onto a thermostated printing plate. Following every printed layer, the printing plate is lowered by a predefined distance (layer height), thus allowing the printing head to create another layer of material on the top of a printed object. The software of a 3D printer controls the temperature of a printing head and plate, the moving speed of a printing head, gel extrusion rates, and other settings.

The printing experiments were carried out with three different PEO concentrations (X1): 10\%, 15\% and 20\% (Table 1). The effects of a printing head speed (X2) and printing plate temperature (X3) on the overall printability of PEO gels were evaluated as independent process parameters (Table 1). The printing head speeds (X2) studied were $0.5 \mathrm{~mm} / \mathrm{s}, 1.0$ $\mathrm{mm} / \mathrm{s}$ and $1.5 \mathrm{~mm} / \mathrm{s}$. The printing plate temperature $(\mathbf{X 3})$ was set at $30^{\circ} \mathrm{C}, 50^{\circ} \mathrm{C}$ or $70^{\circ} \mathrm{C}$. All other process parameters, such as layer height, extrusion speed, needle size, and temperature in the printing head were kept constant. The responses studied were the

lattice weight (mg) (Y1), lattice area $\left(\mathrm{mm}^{2}\right)(\mathrm{Y} 2)$, and lattice area ratio $\left(\mathrm{r}_{\mathrm{s}}\right)(\mathrm{Y} 3)($ Table 1).

Table 1. Full factorial design matrix $\left(3^{3}\right)$ and the results $(n=3)$

\section{Independent parameter* Response*}


Journal Pre-proofs

\begin{tabular}{|c|c|c|c|c|c|c|}
\hline Exp. & $\mathrm{X} 1$ & $\mathrm{X} 2$ & $\mathrm{X} 3$ & $\mathrm{Y} 1$ & Y2 & Y3 \\
\hline 1 & -1 & -1 & -1 & $24.5 \pm 12.1$ & $162.7 \pm 41.3$ & $1.01 \pm 0.26$ \\
\hline 2 & -1 & -1 & 0 & $30.2 \pm 7.2$ & $149.4 \pm 4.9$ & $0.93 \pm 0.03$ \\
\hline 3 & -1 & -1 & +1 & $47.0 \pm 21.0$ & $245.2 \pm 79.8$ & $1.52 \pm 0.50$ \\
\hline 4 & -1 & 0 & -1 & $27.8 \pm 0.6$ & $202.0 \pm 27.8$ & $1.26 \pm 0.17$ \\
\hline 5 & -1 & 0 & 0 & $37.8 \pm 19.6$ & $195.2 \pm 16.0$ & $1.21 \pm 0.10$ \\
\hline 6 & -1 & 0 & +1 & $26.4 \pm 13.3$ & $136.8 \pm 25.7$ & $0.85 \pm 0.16$ \\
\hline 7 & -1 & +1 & -1 & $25.6 \pm 6.3$ & $240.9 \pm 82.4$ & $1.50 \pm 0.51$ \\
\hline 8 & -1 & +1 & 0 & $29.8 \pm 1.9$ & $152.8 \pm 15.3$ & $0.95 \pm 0.09$ \\
\hline 9 & -1 & +1 & +1 & $34.2 \pm 4.9$ & $169.8 \pm 20.9$ & $1.06 \pm 0.13$ \\
\hline 10 & 0 & -1 & -1 & $44.3 \pm 2.0$ & $154.7 \pm 33.4$ & $0.96 \pm 0.21$ \\
\hline 11 & 0 & -1 & 0 & $43.8 \pm 1.8$ & $190.0 \pm 32.1$ & $1.18 \pm 0.20$ \\
\hline 12 & 0 & -1 & +1 & $44.9 \pm 3.3$ & $186.0 \pm 3.3$ & $1.16 \pm 0.02$ \\
\hline 13 & 0 & 0 & -1 & $56.1 \pm 13.6$ & $23 \overline{0.7} \pm 28.3$ & $1.43 \pm 0.18$ \\
\hline 14 & 0 & 0 & 0 & $44.4 \pm 4.6$ & $151.0 \pm 26.5$ & $0.94 \pm 0.16$ \\
\hline 15 & 0 & 0 & +1 & $45.8 \pm 4.2$ & $169.7 \pm 31.8$ & $1.06 \pm 0.20$ \\
\hline 16 & 0 & +1 & -1 & $43.8 \pm 7.3$ & $281.7 \pm 13.1$ & $1.75 \pm 0.08$ \\
\hline 17 & 0 & +1 & 0 & $37.9 \pm 5.8$ & $141.9 \pm 5.8$ & $0.88 \pm 0.04$ \\
\hline 18 & 0 & +1 & +1 & $43.6 \pm 1.2$ & $170.0 \pm 27.4$ & $1.06 \pm 0.17$ \\
\hline 19 & +1 & -1 & -1 & $76.8 \pm 15.2$ & $188.1 \pm 20.9$ & $1.17 \pm 0.13$ \\
\hline 20 & +1 & -1 & 0 & $53.1 \pm 11.3$ & $153.3 \pm 18.3$ & $0.95 \pm 0.11$ \\
\hline 21 & +1 & -1 & +1 & $71.3 \pm 9.6$ & $171.8 \pm 36.7$ & $1.07 \pm 0.23$ \\
\hline 22 & +1 & 0 & -1 & $56.4 \pm 2.3$ & $208.1 \pm 98.8$ & $1.29 \pm 0.61$ \\
\hline 23 & +1 & 0 & 0 & $46.2 \pm 9.5$ & $126.2 \pm 5.8$ & $0.78 \pm 0.04$ \\
\hline 24 & +1 & 0 & +1 & $57.6 \pm 11.1$ & $112.5 \pm 7.2$ & $0.70 \pm 0.04$ \\
\hline 25 & +1 & +1 & -1 & $51.4 \pm 1.6$ & $210.9 \pm 34.0$ & $1.31 \pm 0.21$ \\
\hline 26 & +1 & +1 & 0 & $53.7 \pm 2.5$ & $134.1 \pm 7.7$ & $0.83 \pm 0.05$ \\
\hline 27 & +1 & +1 & +1 & $57.8 \pm 8.1$ & $137.6 \pm 4.1$ & $0.86 \pm 0.03$ \\
\hline
\end{tabular}

*Key: X1 = Concentration of PEO solution: 10\% (-1), 15\% (0), $20 \%(+1) ; X 2$ = Printing head speed $(\mathrm{mm} / \mathrm{s}): 0.5(-1), 1.0(0), 1.5(+1) ; \mathrm{X3}=$ Printing plate temperature $\left({ }^{\circ} \mathrm{C}\right): 30(-1), 50(0)$, $70(+1) . Y 1=$ Lattice weight $(\mathrm{mg}) ; \mathrm{Y} 2=$ Lattice area $\left(\mathrm{mm}^{2}\right) ; \mathrm{Y3}=$ Lattice area ratio $\left(\mathrm{r}_{\mathrm{s}}\right)$.

The potential thermal-induced changes of a carrier polymer (PEO) in 3D extrusionbased printing were investigated by fabricating three additional $20 \times 20 \times 1 \mathrm{~mm}$ full squares 
(lattices). The same three printing plate temperatures were used (e.g. $30^{\circ} \mathrm{C}, 50^{\circ} \mathrm{C}$ and $70{ }^{\circ} \mathrm{C}$ ). The PEO concentration of the aqueous gel was $15 \%$. The printing speed was set at $1.0 \mathrm{~mm} / \mathrm{s}$. The 3D-printed lattices were stored in closed zip-lock bags until further studies. The solidstate analysis of the 3D-printed lattices was conducted as described in the later chapters.

\subsection{Evaluation of printability}

The evaluation of 3D printability was based on the lattice weight, dimensions and area measurements. Each printed polymeric lattice was carefully weighed with an analytical scale and photographed using a digital single-lens reflex camera Nikon D3300 (Nikon, Japan). The photographs were analysed with an ImageJ (National institute of Health, U.S.) image analysis software (version $1.51 \mathrm{k}$ ) [32].The area was automatically calculated from a black-and-white image based on a threshold value. This experimental value was then compared with the theoretical area value of a designed lattice. The ratio of areas was calculated as the ratio of experimental area to the theoretical area (Equation 1):

$$
r_{s}=\frac{s_{e}}{s_{t}}
$$

where $r_{s}$ stands for the calculated ratio, $S_{e}$ for the experimental area and $S_{t}$ for the theoretical lattice area calculated from the designed lattice model. Each printed lattice was individually weighed to assess the uniformity and reproducibility of the 3D-printed PEO lattices. 
The effects of PEO concentration (X1), printing head speed (X2) and printing plate temperature (X3) on over all printability of PEO gels were modelled using the following second-order polynomial Equation 2:

$$
\begin{aligned}
& Y=a 1 \cdot X 1+a 2 \cdot X 2+a 3 \cdot X 3+a 4 \cdot X 1 \cdot X 2+a 5 \cdot X 1 \cdot X 3+a 6 \cdot X 2 \cdot X 3+a 7 \cdot X 1^{2} \\
& +a 8 \cdot X 2^{2}+a 9 \cdot X 3^{2}+c o n s t a n t
\end{aligned}
$$

where $\mathrm{Y}=$ response and $\mathrm{a} 1 \ldots \mathrm{a} 9=$ coefficients.

The model was reduced with a multi-linear backward, step-wise regression technique. The least significant terms were excluded from the model as long as the predictive power $\left(\mathrm{Q}^{2}\right)$ of the model was increasing (Table 2). The modelling was performed using Modde for Windows (Version 7.0.0.1, Umetrics, Sweden).

Table 2. The fitted models for unscaled cofficients and responses

\begin{tabular}{llll}
\hline Coefficient & Y1 & Y2 & Y3 \\
\hline a1 & 2.68 & 3.12 & 0.0186 \\
a2 & -6.46 & 152 & 0.940 \\
a3 & NS & -4.68 & -0.0299 \\
a4 & NS & NS & NS \\
a5 & NS & -0.110 & -0.000667 \\
a6 & NS & -2.95 & -0.0183 \\
a7 & NS & NS & NS \\
a8 & NS & NS & NS \\
a 9 & NS & 0.0821 & 0.000517 \\
constant & 11.2 & 215 & 1.36 \\
\hline$R^{2}$ & 0.746 & 0.682 & 0.681 \\
$Q^{2}$ & 0.668 & 0.411 & 0.410 \\
\hline
\end{tabular}

NS $=$ not significant 
The final appearance of the polymeric lattices was assessed by visual inspection. The visual assessment group consisted of total 10 persons, who independently (and in a randomized blinded order) gave the ranking quality points to the 3D-printed lattices. The assessment group was given a reference lattice printed with acrylonitrile butadiene styrene. The ranking quality points ranged from 1 (indicating the poorest quality) to 10 (indicating the best quality).

\subsection{Fourier-transform infrared (FTIR) spectroscopy}

The FTIR spectra of the printed PEO squares were obtained using an IRPrestige-21 spectrophotometer (Shimadzu Corp., Japan) and Specac Golden Gate Single Reflection attenuated total reflection (ATR) crystal (Specac Ltd., UK). The analytical range was from 600 $\mathrm{cm}^{-1}$ to $4000 \mathrm{~cm}^{-1}$. All spectra were an average of 60 spectra, normalised and baseline corrected.

\section{7. $X$-ray diffraction $(X R D)$}

The samples were studied by XRD using the Bruker D8 Advance diffractometer with Ni filtered $\mathrm{Cu} K \alpha$ radiation, $0.3^{\circ}$ divergence slit, two $2.5^{\circ}$ Soller slits and LynxEye line detector. Scanning steps of $0.022 \theta$ from 5 to $35^{\circ} 2 \theta$ and a total counting time of 166 s per step were used.

\subsection{Data analysis}

All the data are presented as a mean \pm standard deviation. The influence of the process parameters was evaluated using regression analysis. All tests were carried out using MS Excel. 


\section{Results and discussion}

\subsection{Viscosity of the aqueous PEO gels intended for $3 D$ printing}

The rheology of aqueous PEO gels followed a shear-thinning (also known as pseudoplastic) behaviour at all PEO concentrations studied (Figure 1). These results are in good agreement with the findings on the rheological behaviour of PEO gels reported in the literature [33]. In our study, the viscosity of the aqueous PEO gels increased together with the polymer concentration at all shear rates used. The viscosity of the present gels intended for extrusionbased 3D printing ranged from $24.4 \pm 1.1 \mathrm{~Pa} \cdot \mathrm{s}$ to $186.7 \pm 6.8 \mathrm{~Pa} \cdot \mathrm{s}$ at a shear rate of $10 \mathrm{~s}^{-1}$. Perhaps surprisingly, the viscosity of aqueous PEO gels used in our study was even ten-tohundreds time lower than those reported in the literature for 3D printing by using gels of different materials [34,35]. However, Bakarich et al. [16] found that less viscous gels (similar to the PEO gels used in our study) are also applicable for extrusion-based bioprinting. It is evident that the successful 3D printing with low-viscosity PEO gels is partially attributed to the shear-thinning rheology of PEO gel. Shear thinning response and high near-zero viscosity has been reported as highly desirable in the context of liquid deposition modelling (LDM)-based 3D printing. In an extrusion-based printing, extrusion through a capillary nozzle at high shear-rates has been shown to decrease the viscosity of a printing material $[34,36]$.

We observed that the viscosity behaviour of gels can be used for predicting the extrusion-based 3D printability of a carrier polymer. By knowing the range of viscosity profiles of the gels suitable for extrusion-based 3D printing, we can readily assess the expected printability of the material as well. Therefore, the gel viscosity of a carrier polymer is a crucial material parameter affecting the 3D-printability of the system. It is also important 


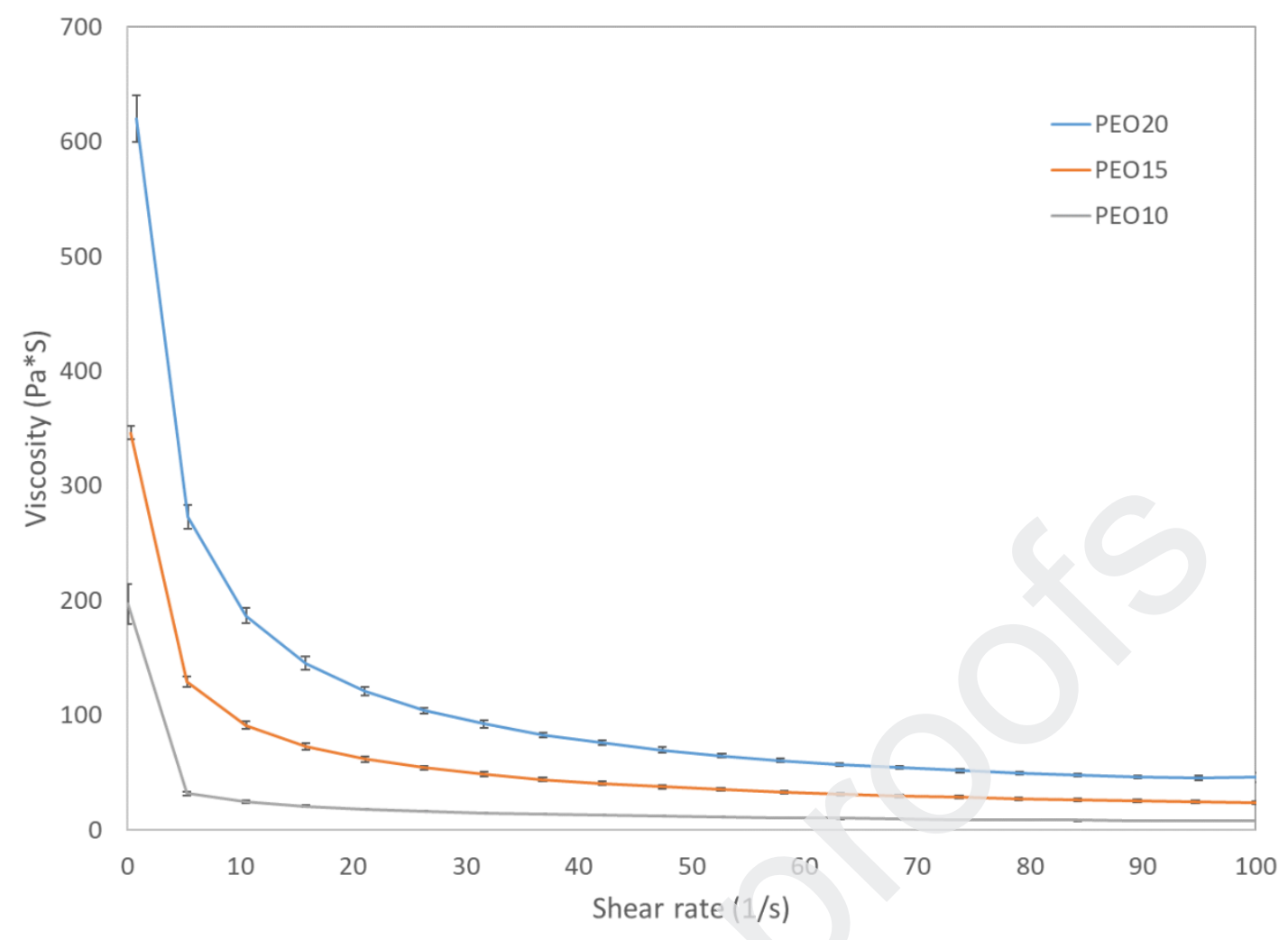

Fig. 1. Viscosity of PEO gels $\left(25^{\circ} \mathrm{C}\right)$ intended for $3 \mathrm{D}$ printing. Key: PEO10 $=10 \%$ aqueous PEO gel; PEO15 $=15 \%$ aqueous PEO gel; PEO20 $=20 \%$ aqueous PEO gel.

important to find the most suitable printing parameters for such polymer(s), and to gain understanding of the printing process. This will in turn contribute finding more promising biocompatible polymers that can be applied in medical and/or pharmaceutical 3D printing. According to the literature, crosslinking of polymer can also increase the viscosity, and consequently, enhance printing low viscosity polymer inks [37]. The crosslinked Pluronic F127 gels with different polymer concentrations (viscosity ranging from $30 \mathrm{mPa} \cdot \mathrm{s}$ to over 60 $\left.\times 10^{6} \mathrm{mPa} \cdot \mathrm{s}\right)$ were successfully applied in $3 \mathrm{D}$ printing [38]. The known viscosity profile and 3D-printing process correlation can be further taken into consideration when choosing the design pattern and printing parameters. 


\subsection{D-printability of aqueous PEO gels}

\subsubsection{Appearance of the $3 D$ printed polymeric lattices}

The extrusion-based 3D printing of the model lattices using aqueous PEO gels was found to be possible at all printing parameter levels included in the experimental design. The general morphology and printing accuracy of the lattices, however, varied significantly. As shown in Figure 2, the overall appearance and quality of the printed lattices were improved as the PEO concentration of the gels (and therefore also the gel viscosity) was increased. The two most common defects of the 3D-printed lattices were a dumbbell-shaped lattice and the fusion of separate printed layers, thus indicating unsat isfactory 3D-printing. The quality grades given to the $3 \mathrm{D}$-printed lattices by independent visual inspection $(\mathrm{n}=10)$ were in agreement with the results obtained in the further characterisation of the printed lattices. Calculating the area of printed lattices by image analysis and comparing it with the theoretical area of a designed model enabled us to evaluate the printability of aqueous PEO gels and influence of process parameters on the $3 \mathrm{D}$ printing.

\subsubsection{Weight and weight variation of the $3 D$ printed polymeric lattices}

The PEO concentration (X1) had a positive effect on the weight of the extrusion-based 3D printed lattices $\left(\mathbf{R}^{\mathbf{2}}=\mathbf{0 . 9 9 9 5}\right)$. If higher concentration of PEO $\mathbf{( 2 0 \% )}$ was used in 3D printing, more polymer was deposited during printing, thus resulting in a slight overall increase in the weights of 3D-printed PEO lattices (Figures 3A and 3B). The average weights for the 3D-printed lattices were $31.5 \pm 9.7 \mathrm{mg}$ (PEO gel concentration of 10\%), $45.0 \pm 4.9 \mathrm{mg}(15 \%)$ and $58.2 \pm 7.9 \mathrm{mg}(20 \%)$, respectively. 
A

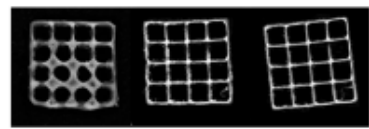

$0.5 \mathrm{~mm} / \mathrm{s} 30^{\circ} \mathrm{C}$

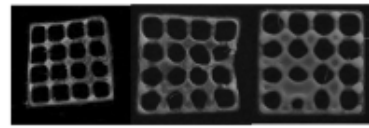

$1 \mathrm{~mm} / \mathrm{s} 30^{\circ} \mathrm{C}$

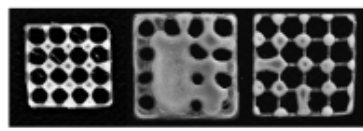

$1.5 \mathrm{~mm} / \mathrm{s} 30^{\circ} \mathrm{C}$

B

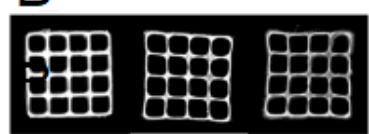

$0.5 \mathrm{~mm} / \mathrm{s} 30^{\circ} \mathrm{C}$

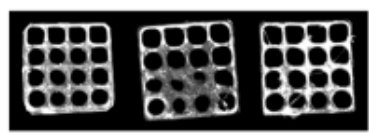

$1 \mathrm{~mm} / \mathrm{s} 30^{\circ} \mathrm{C}$



$1.5 \mathrm{~mm} / \mathrm{s} 30^{\circ} \mathrm{C}$

C

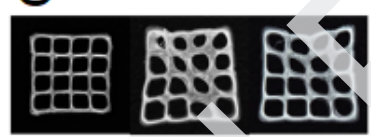

$0.5 \mathrm{~mm} / \mathrm{s} 30$
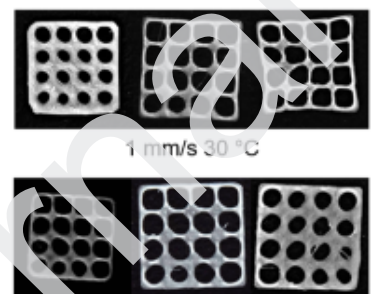

$1.5 \mathrm{~mm} / \mathrm{s} 30^{\circ} \mathrm{C}$

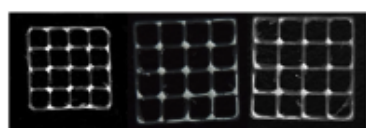

$0.5 \mathrm{~mm} / \mathrm{s} 50^{\circ} \mathrm{C}$

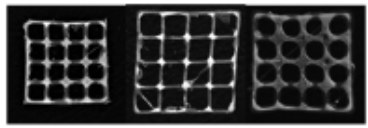

$1 \mathrm{~mm} / \mathrm{s} 50^{\circ} \mathrm{C}$

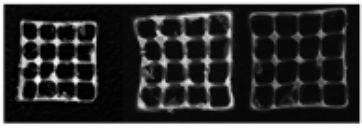

$1.5 \mathrm{~mm} / \mathrm{s} 50^{\circ} \mathrm{C}$

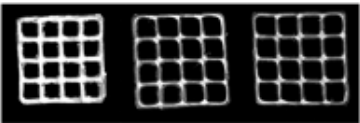

$0.5 \mathrm{~mm} / \mathrm{s} 50^{\circ} \mathrm{C}$
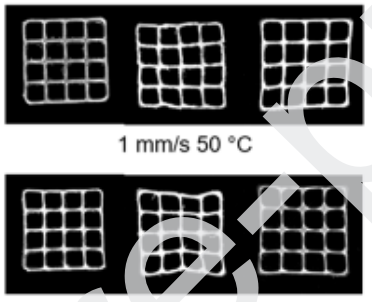

$1.5 \mathrm{~m} / \mathrm{n} / \mathrm{s} 50^{\circ} \mathrm{C}$

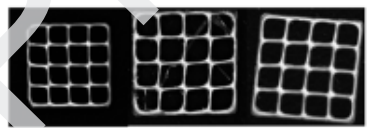

$0.5 \mathrm{~mm} / \mathrm{s} 50^{\circ} \mathrm{C}$
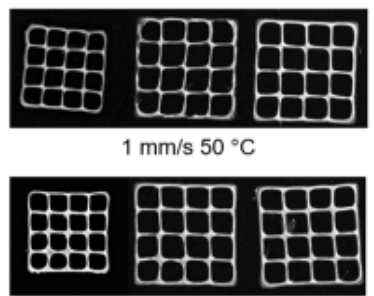

$1.5 \mathrm{~mm} / \mathrm{s} 50^{\circ} \mathrm{C}$

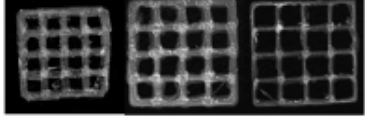

$0.5 \mathrm{~mm} / \mathrm{s} 70^{\circ} \mathrm{C}$

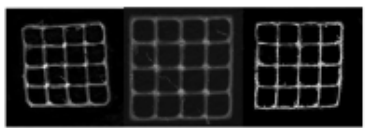

$1 \mathrm{~mm} / \mathrm{s} 70^{\circ} \mathrm{C}$

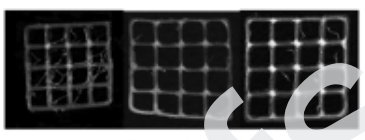

$1.5 \mathrm{~mm} / \mathrm{s} 70^{\circ} \mathrm{C}$



$0.5 \mathrm{~mm} / \mathrm{s} 70^{\circ} \mathrm{C}$
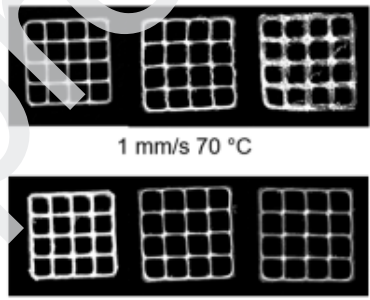

$1.5 \mathrm{~mm} / \mathrm{s} 70^{\circ} \mathrm{C}$

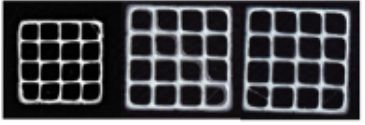

$0.5 \mathrm{~mm} / \mathrm{s} 70^{\circ} \mathrm{C}$
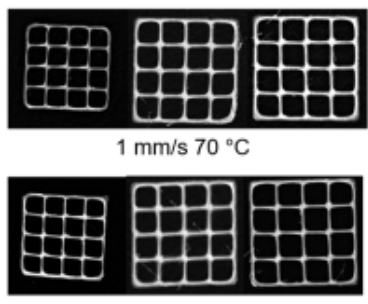

$1.5 \mathrm{~mm} / \mathrm{s} 70^{\circ} \mathrm{C}$

Fig. 2. Photographs of the 3D printed PEO lattices. The three independent variables in the factorial experimental design are given in Table 1. A, B and C denote lattices printed with $10 \%, 15 \%$ or $20 \%$ PEO gels accordingly. 

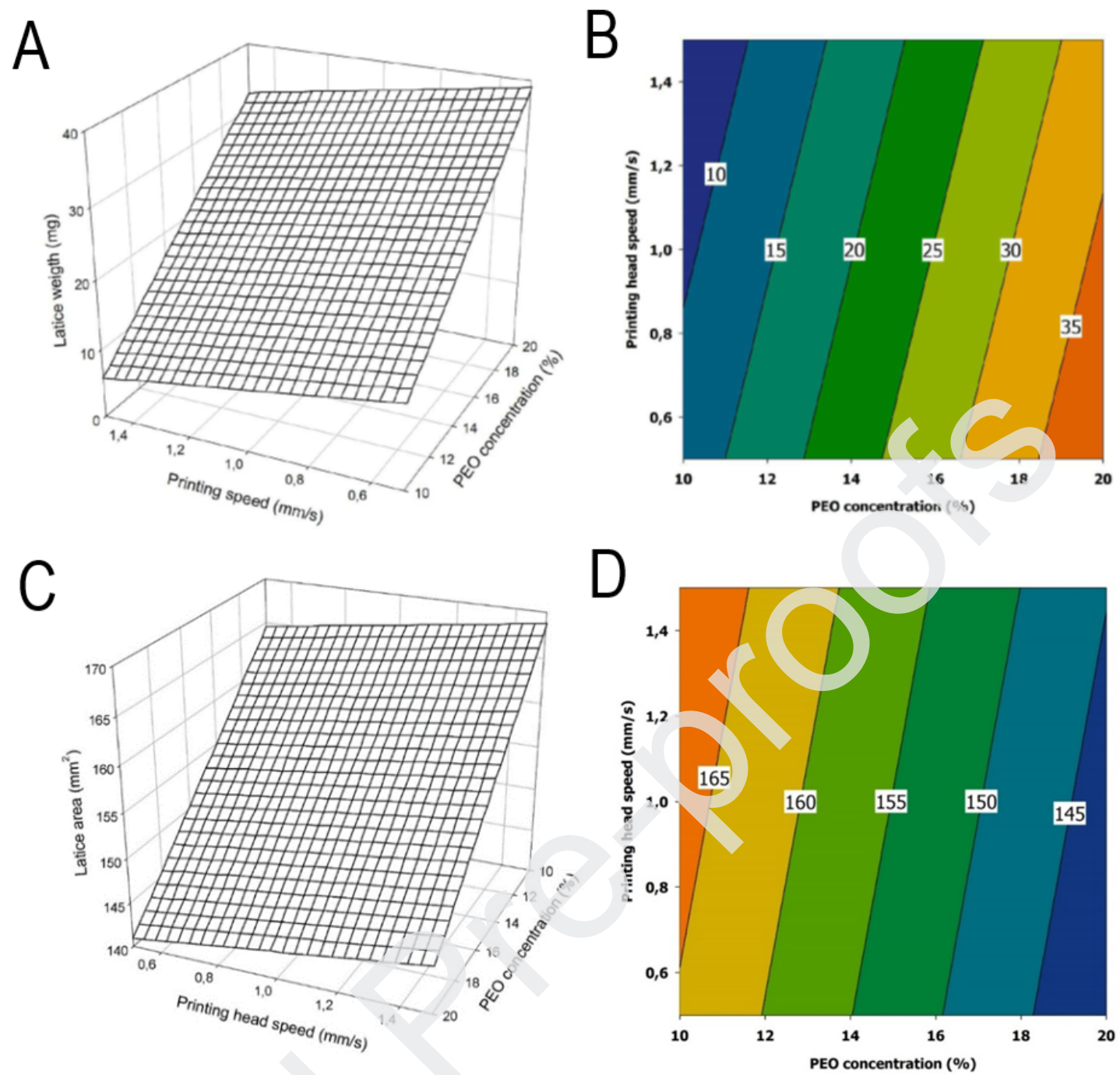

Fig. 3. Effects of the PEO concentration and printing head speed $(\mathrm{mm} / \mathrm{s})$ on the weight $(\mathrm{mg})$ $(A, B)$ and lattice area $\left(\mathrm{mm}^{2}\right)(\mathrm{C}, \mathrm{D})$ of the 3D printed polymeric lattices $(\mathrm{n}=3)$. A. Surface plot $(\mathrm{A}, \mathrm{C})$ and contour plot $(\mathrm{B}, \mathrm{D})$ presentations. Reference is also made to Table 1.

In addition to PEO concentration (X1), a printing head speed (X2) (i.e., the movement speed of a printing head on $\mathrm{X}-\mathrm{Y}$ axis) affected the lattice weight. Since a gel-extrusion speed was kept constant, the printing head speed determines the time to complete the lattice printing and the amount of material deposited during that time. Therefore, as a printing head speed (X2) was decreased (longer time to complete printing), a slight 
increasing trend in a lattice weight was observed (Figures $3 \mathrm{~A}, 3 \mathrm{~B}$ ). The printing plate temperature (X3) did not affect the weight of the extrusion-based 3D printed lattices.

\subsubsection{Surface area of the $3 D$ printed polymeric lattices}

According to the literature, extrusion-based (fused deposition) 3D-printing can result in the thermal contraction and shrinkage of the printed objects [39]. The effects of a printing head speed (X2) on the area of 3D-printed lattices at different PEO concentrations are shown in Figures 3C and 3D. Increasing the printing head speed (X2) and decreasing the PEO gel concentration (X1) led to larger area of the 3D printed lattices. It is evident that by using a higher printing head speed (X2), the gel material for one layer will be deposited faster, thus shortening the gap time before the next layer is printed. As shown in Figure 1, the PEO gels studied exhibit pseudoplastic behaviour, thus interfering with the gel settling. In addition, if a new layer is printed before the previous gel layer has not dried completely, the mass of the next layer will cause the deformation of the previous layer. This effect was seen with all 3D printing formulations studied here.

The printing plate temperature $(\mathrm{X3})$ had a significant influence on the surface area of the 3D printed lattices $(\mathbf{p}<\mathbf{0 . 0 5})$. The increase of a printing plate temperature $(\mathrm{X} 3)$ resulted in a clear decrease of the surface area of the 3D printed lattices (Figure 4). This decrease in a lattice surface area was observed with all PEO gel concentrations (X1) studied but it was especially prominent with a PEO $20 \%$ gel concentration (Figure 4). The higher viscosity PEO gels were capable of keeping their initial shape on the course of a curing time, while lower viscosity gels exhibited deformation. The higher printing plate temperature enhances the drying of the previous gel layer prior to printing the subsequent layer onto it. 


\section{Journal Pre-proofs}

As shown in Figure 5, increasing a printing plate temperature (X3) lead to a clear decrease of the surface area of the 3D printed lattices at the printing head speed (X2) settings higher than $1.0 \mathrm{~mm} / \mathrm{s}$. Since the extrusion speed is kept constant, the amount of extruded material per lattice surface area is dependent on a printing head speed (X2) creating visually thinner print lines at higher printing speed levels and thicker print lines at lower printing speed levels. This in turn results in either smaller or larger 3D printed lattice surface areas, respectively. Interestingly, a printing head speed (X2) had a twofold effect on a lattice surface area: a positive effect as the lowest printing plate temperature $\left(30^{\circ} \mathrm{C}\right)$ was used, and a negative effect at the highest printing plate temperature $\left(70^{\circ} \mathrm{C}\right)$ used. However, these contradiction effects could not be explained by the amount of the extruded material per a lattice surface area. We feel that further studies are needed to gain understanding of this phenomenon.

Printing head speed had a positive effect on the 3D lattice area at low printing plate temperature levels and negative effect on the present response at high printing plate temperatures (Figure 5). As discussed earlier, when the PEO gel is not exposed to higher temperature, print lines will be deformed by the flow of the material itself and the mass of the next layer. This results in the increase of the print line width. As the drying of the gel material is aided by elevated printing plate temperature, the lines remain thinner. Since the model lattice grid consists of one print line, the width of this line determines the overall lattice area. However, higher temperature during 3D printing may affect other relevant properties of polymers as well as drug substances when incorporated into the DDSs [40], hence these effects need to be separately investigated. In the present study the solid-state properties of the 3D printed lattices were tested and compared to raw materials. 

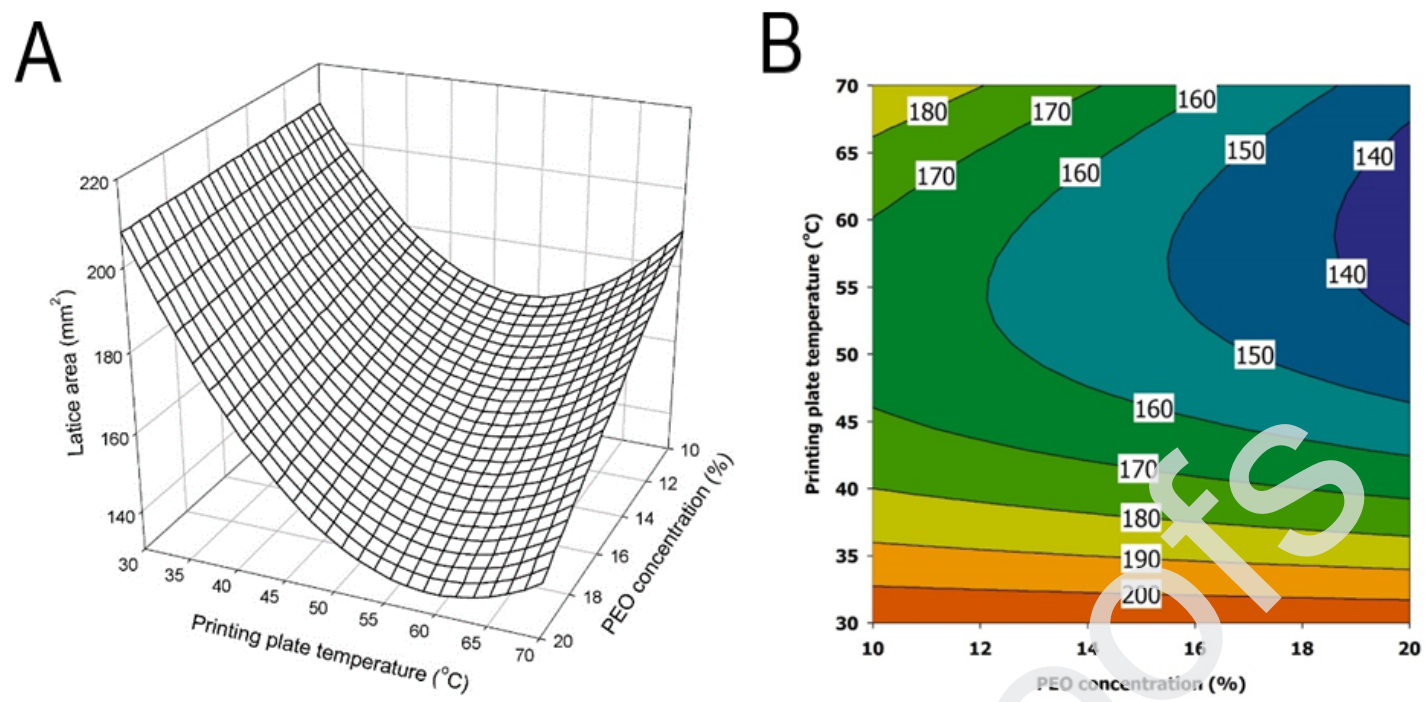

Fig. 4. Effects of the PEO concentration and printing plate temperature $\left({ }^{\circ} \mathrm{C}\right)$ on the lattice area $\left(\mathrm{mm}^{2}\right)$ of the 3D printed polymeric lattices $(\mathrm{n}=3)$. A surface plot (A) and contour plot (B) presentation. Reference is also made to Table 1.


Fig. 5. Effects of the printing head speed $(\mathrm{mm} / \mathrm{s})$ and printing plate temperature $\left({ }^{\circ} \mathrm{C}\right)$ on the lattice area $\left(\mathrm{mm}^{2}\right)$ of the 3D printed polymeric lattices $(\mathrm{n}=3)$. A. Surface plot $(\mathrm{A})$ and contour plot (B) presentation. Reference is also made to Table 1. 


\subsubsection{Surface area ratio of the $3 D$ printed polymeric lattices}

The lattice area measurements of the 3D-printed objects give us information only on the layer formation behaviour of the gel material during printing. These measurements, however, do not directly indicate it, if the printability of the gel is good or poor. To evaluate the true printability, the actual value of the surface area of the 3D-printed lattice was compared to the theoretical lattice area $\left(160.89 \mathrm{~mm}^{2}\right)$. As shown previously in Figures 3C and 3D, the use of higher printing head speed resulted in a slightly larger area of the 3D-printed PEO lattices. The lattice area ratio $\left(r_{x}\right)$ (i.e., the ratio of the areas of an experimental and theoretical lattice) was similarly affected by both the printing head speed and PEO gel concentration (Figure 6). According to the model (as seen in Figure 6), the area of the experimental 3Dprinted lattice is closest to the theoretical value when the PEO concentration of the gel is $12 \%$ and the printing head speed used is $1.0 \mathrm{~mm} / \mathrm{s}$. 

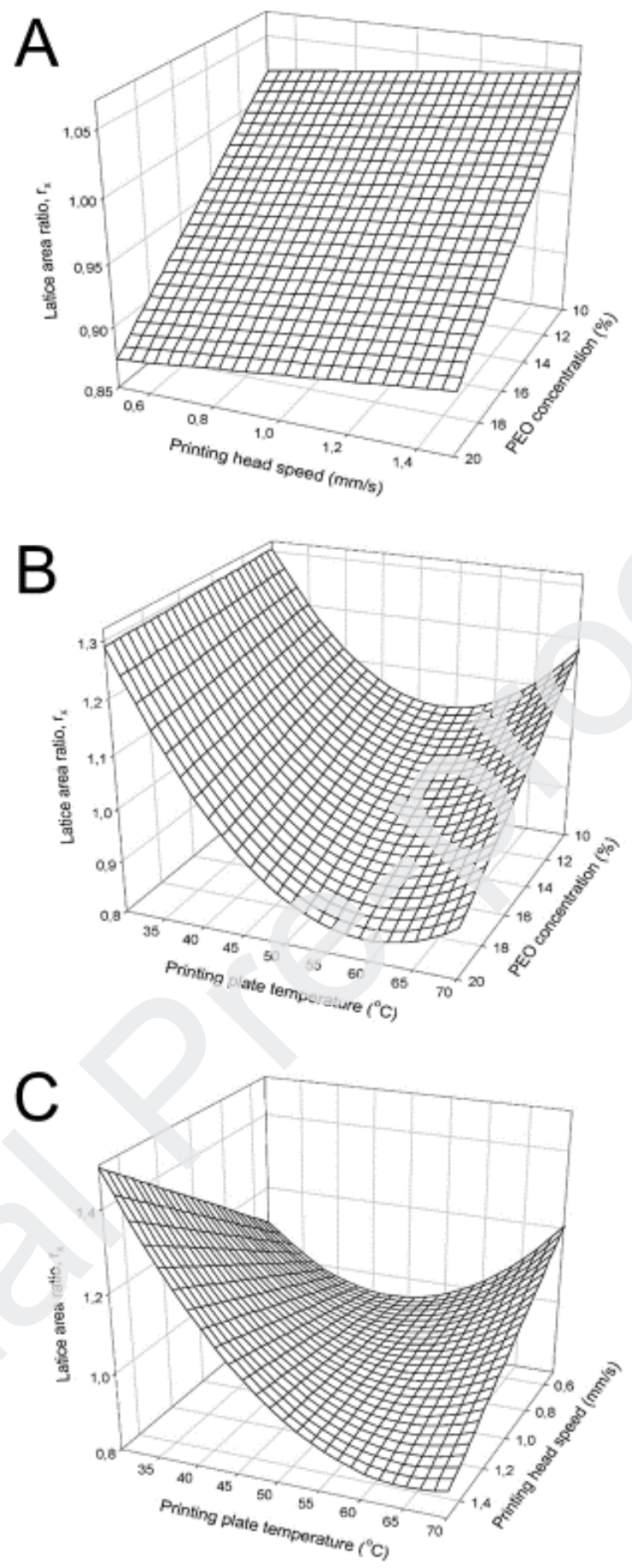

Fig. 6. Effects of the PEO concentration (A, B), printing head speed $(\mathrm{mm} / \mathrm{s})(\mathrm{A}, \mathrm{C})$, printing plate temperature $\left({ }^{\circ} \mathrm{C}\right)(\mathrm{B}, \mathrm{C})$ on the lattice area ratio $\left(\mathrm{r}_{\mathrm{x}}\right)$ of the $3 \mathrm{D}$ printed polymeric lattices $(\mathrm{n}=3)$. Reference is also made to Table 1 . 
As seen from current study, the 3D printing process accuracy is influenced by more than one parameter at once, with the combination of printing plate temperature and printing head speed being the most prevalent $(\mathrm{p}=0.002)$. The present results suggest that the most challenging combination of the process parameters in terms of 3D printability is the high printer head speed (Figure 6A) and low plate temperature (Figure 6B). With the 3D-printed lattices, the measured area was larger than the theoretical value. Also, instead of a straight-lined grid, dumbbell shaped lattices were formed. Similar material spreading effect suggesting insufficient printability has also been observed in literature. $[9,23,41]$ Heating up the printing plate results in faster drying of the printed PEO gels, thus allowing a faster printer head speed to be used (Figure 6C). The application of a faster printer head speed in turn lead to more precise 3D printing. With some other 3D-printed lattices (especially with those printed with a high PEO gel concentration), the experimental lattice area was smaller than the theoretical value (Figures 6A and 6B). The possible reasons for this phenomenon were discussed already in the previous section.

\subsection{Thermal-induced solid-state changes}

To verify whether any unexpected solid-state transformations took place at the utilized printing settings, we also conducted the solid-state analyses for the samples. It is well known that solid state transformations can have a great impact on the final per formance and stability of DDSs. In our study, the printing plate temperatures above $70^{\circ} \mathrm{C}$ were not studied due to the possible melting of PEO. Therefore, the elevated temperatures higher than $70^{\circ} \mathrm{C}$ are not considered as applicable for the $3 \mathrm{D}$ printing process described here. 
According to the literature, PEO degrades at elevated temperatures [42]. In the present extrusion-based 3D printing, the aqueous PEO gel and printed lattices were exposed to the printing plate temperatures ranging from $30{ }^{\circ} \mathrm{C}$ to $70{ }^{\circ} \mathrm{C}$. The printing contact time ranged from $20 \mathrm{~min}$ to $60 \mathrm{~min}$. The melting temperature of PEO is approximately $65^{\circ} \mathrm{C}$ [43]. In the present study, no visible melting of the carrier material was detected when the PEO gel was printed onto a plate at the temperature of $70{ }^{\circ} \mathrm{C}$ for up to $60 \mathrm{~min}$. The possible thermal-induced solidstate changes of PEO in extrusion-based 3D printing were investigated by means of FTIR spectroscopy and XRD. Figure 7A shows the FTIR spectra of the 3D printed PEO squares. Two significant absorption complexes were displayed between $2960 \mathrm{~cm}^{-1}$ and $2890 \mathrm{~cm}^{-1}$ and around $1100 \mathrm{~cm}^{-1}$ representing methylene stretching and a combination of ether group and methylene group stretching, respectively. The present results are in line with the earlier findings in the literature [44]. An increase in the intensity of absorption can be seen at approximately $2875 \mathrm{~cm}^{-1}$ with the increase of the printing plate temperature.


Fig. 7. Fourier-transform infrared (FTIR) spectra (A) and X-ray diffraction (XRD) patterns (B) of PEO polymer and 3D printed PEO squares printed on different plate temperatures. 
PEO shows two distinctive diffraction peaks at $2 \theta=19^{\circ}$ and $23^{\circ}$ [45]. There is a decreasing tendency in the intensity at approximately $23^{\circ}$, observed when elevating the plate temperature. Yet, the XRD patterns do not show any significant difference in the degree of crystallinity between the 3D-printed PEO lattices prepared with different plate temperatures (Figure 7B).

It is known from the literature that the degradation temperature of PEO is ranging from $400{ }^{\circ} \mathrm{C}$ to $450{ }^{\circ} \mathrm{C}$ for high molecular weight $\mathrm{PEO}$ [46-48]. As the temperature will not rise as high during extrusion-based 3D printing process and no apparent solid-state changes were detected at process temperatures, PEO can be also be confirnaed as a plausible model polymer for these printability studies.

\section{Conclusions}

The aqueous PEO gels are applicable in an extrusion-based 3D printing of DDSs (specially designed polymeric lattices). The formulation and process parameters studied here are critical affecting the extrusion-based 3D printing of aqueous PEO gels. The optimization of the levels of PEO gel concentration, printing head speed and printing plate temperature is crucial for a successful and reproducible 3D printing. Extrusion-based 3D printing, however, is a multivariate continuous manufacturing process, and consequently there is a number of other significant printing parameters affecting 3D printing. No thermal-induced solidstate changes of a carrier polymer are expected within the extrusion-based 3D printing of aqueous PEO gels in the temperature range from $30^{\circ} \mathrm{C}$ to $70^{\circ} \mathrm{C}$. 


\section{Declaration of interest}

The authors report no conflicts of interest. The authors alone are responsible for the content and writing of this article.

\section{Data availability}

The raw/processed data required to reproduce these findings cannot be shared at this time as the data also forms part of an ongoing study.

\section{Acknowledgements}

This work is part of the PUT1088 and IUT-34-18 projects and Estonian Research Council and Estonian Ministry of Education and Research are acknowledged. L ORÉAL Baltic “For Women In Science" fellowship 2018 (K. Kogermann) with the support of the Estonian National Commission for UNESCO and the Estonian Academy of Sciences and the L'ORÉAL-UNESCO international program "For Women In Science" is acknowledged. Dr Gunnar Nurk (University of Tartu) is acknowledged for providing the facilities and helping with the rheology measurements. Prof Kalle Kirsimäe and Dr Jaan Aruväli (University of Tartu) are acknowledged for the XRD measurements. 


\section{References}

[1] S. V Murphy, A. Skardal, A. Atala, Evaluation of hydrogels for bio-printing applications, (2012). doi:10.1002/jbm.a.34326.

[2] D.M. Kirchmajer, R. Gorkin III, M. in het Panhuis, An overview of the suitability of hydrogel-forming polymers for extrusion-based 3D-printing, J. Mater. Chem. B. 3 (2015) 4105-4117. doi:10.1039/C5TB00393H.

[3] S. Lamichhane, S. Bashyal, T. Keum, G. Noh, J.E. Seo, R. Bastola, J. Choi, D.H. Sohn, S. Lee, Complex formulations, simple techniques: Can 3D printing technology be the Midas touch in pharmaceutical industry?, Asian J. Pharm. Sci. (2019). doi:10.1016/j.ajps.2018.11.008.

[4] Y. He, F. Yang, H. Zhao, Q. Gao, B. Xia, J. Fu, Research on the printability of hydrogels in 3D bioprinting, Sci. Rep. 6 (2016) 1-13. doi:10.1038/srep29977.

[5] D.G. Yu, L. Zhu, C.J. Branford-white, X.L. Yang, Three-Dimensional Printing in Pharmaceutics : Promises and Problems, 97 (2008) 3666-3690. doi:10.1002/jps.

[6] G.M. Paul, A. Rezaienia, P. Wen, S. Condoor, N. Parkar, W. King, T. Korakianitis, Medical Applications for 3D Printing: Recent Developments., Mo. Med. 115 (2018) $75-81$.

[7] Q. Yan, H. Dong, J. Su, J. Han, B. Song, Q. Wei, Y. Shi, A Review of 3D Printing Technology for Medical Applications, Engineering. 4 (2018) 729-742. doi:10.1016/J.ENG.2018.07.021.

[8] H.N. Chia, B.M. Wu, Recent advances in 3D printing of biomaterials, J. Biol. Eng. 9 (2015) 4. doi:10.1186/s13036-015-0001-4.

[9] A. Habib, V. Sathish, S. Mallik, B. Khoda, 3D printability of alginate-carboxymethyl cellulose hydrogel, Materials (Basel). 11 (2018). doi:10.3390/ma11030454. 
[10] S. Kyle, Z.M. Jessop, A. Al-Sabah, I.S. Whitaker, 'Printability' of Candidate Biomaterials for Extrusion Based 3D Printing: State-of-the-Art,' Adv. Healthc. Mater. 6 (2017) 1-16. doi:10.1002/adhm.201700264.

[11] N. Paxton, W. Smolan, T. Böck, F. Melchels, J. Groll, T. Jungst, Proposal to assess printability of bioinks for extrusion-based bioprinting and evaluation of rheological properties governing bioprintability, Biofabrication. 9 (2017) 044107. doi:10.1088/1758-5090/aa8dd8.

[12] J. Aho, J.P. Boetker, S. Baldursdottir, J. Rantanen, Rheology as a tool for evaluation of melt processability of innovative dosage forms, Int. J. Pharm. (2015). doi:10.1016/j.ijpharm.2015.02.009.

[13] Y. He, F. Yang, H. Zhao, Q. Gao, B. Xia, J. Fu, Research on the printability of hydrogels in 3D bioprinting, Sci. Rep. 6 (2016) 29977. doi:10.1038/srep29977.

[14] S.C. Joshi, Sol-Gel Behavior of Hyd oxypropyl Methylcellulose (HPMC) in Ionic Media Including Drug Release, Materials (Basel). 4 (2011) 1861-1905. doi:10.3390/ma4101861.

[15] J. Herzberger, K. Niederer, H. Pohlit, J. Seiwert, M. Worm, F.R. Wurm, H. Frey, Polymerization of Ethylene Oxide, Propylene Oxide, and Other Alkylene Oxides: Synthesis, Noveı Polymer Architectures, and Bioconjugation, (2015). doi:10.1021/acs.chemrev.5b00441.

[16] D.B. Kolesky, R.L. Truby, A.S. Gladman, T.A. Busbee, K.A. Homan, J.A. Lewis, 3D bioprinting of vascularized, heterogeneous cell-laden tissue constructs, Adv. Mater. 26 (2014) 3124-3130. doi:10.1002/adma.201305506.

[17] K.C. Hung, C.S. Tseng, S.H. Hsu, Synthesis and 3D Printing of biodegradable polyurethane elastomer by a water-based process for cartilage tissue engineering applications, Adv. Healthc. Mater. 3 (2014) 1578-1587. 
doi:10.1002/adhm.201400018.

[18] B. Arafat, M. Wojsz, A. Isreb, R.T. Forbes, M. Isreb, W. Ahmed, T. Arafat, M.A. Alhnan, Tablet fragmentation without a disintegrant: A novel design approach for accelerating disintegration and drug release from 3D printed cellulosic tablets, Eur. J. Pharm. Sci. 118 (2018) 191-199. doi:10.1016/j.ejps.2018.03.019.

[19] Q. Li, X. Guan, M. Cui, Z. Zhu, K. Chen, H. Wen, D. Jia, J. Hou, W. Xu, X. Yang, W. Pan, Preparation and investigation of novel gastro-floating tablets with $3 \mathrm{D}$ extrusionbased printing, Int. J. Pharm. 535 (2018) 325-332. doi:10.1016/j.ijpharm.2017.10.037.

[20] S.A. Khaled, J.C. Burley, M.R. Alexander, J. Yang, C.J. Roberts, 3D printing of tablets containing multiple drugs with defined release profiles, Int. J. Pharm. 494 (2015) 643-650. doi:10.1016/j.ijpharm.2015.07.067

[21] W. Jamróz, M. Kurek, E. Łyszczarz, J. Szafraniec, J. Knapik-Kowalczuk, K. Syrek, M. Paluch, R. Jachowicz, 3D printed orodispersible films with Aripiprazole, Int. J. Pharm. 533 (2017) 413-420. doi:10.1016/j.ijpharm.2017.05.052.

[22] W. Jamróz, J. Szafraniec, M. Kurek, R. Jachowicz, 3D Printing in Pharmaceutical and Medical Applications - Recent Achievements and Challenges, Pharm. Res. 35 (2018) 176. doi:10.1007/s11095-018-2454-x.

[23] H. Li, S. L iu, L. Lin, Rheological study on 3D printability of alginate hydrogel and effect of graphene oxide, Int. J. Bioprinting. 2 (2016) 10-12. doi:10.18063/IJB.2016.02.007.

[24] L. Ouyang, R. Yao, Y. Zhao, W. Sun, Effect of bioink properties on printability and cell viability for 3D bioplotting of embryonic stem cells, Biofabrication. 8 (2016). http://iopscience.iop.org/1758-5090/8/3/035020.

[25] F. Yang, M. Zhang, B. Bhandari, Y. Liu, Investigation on lemon juice gel as food material for 3D printing and optimization of printing parameters, LWT - Food Sci. 
Technol. 87 (2018) 67-76. doi:10.1016/j.1wt.2017.08.054.

[26] C.R. Rocha, A.R. Torrado Perez, D.A. Roberson, C.M. Shemelya, E. Macdonald, R.B. Wicker, Novel ABS-based binary and ternary polymer blends for material extrusion 3D printing, J. Mater. Res. 29 (2014) 1859-1866. doi:10.1557/jmr.2014.158.

[27] J. Norman, R.D. Madurawe, C.M. V Moore, M.A. Khan, A. Khairuzzaman, A new chapter in pharmaceutical manufacturing: 3D-printed drug products 弥, 糸访, (2016).

[28] G. Wu, W. Wu, Q. Zheng, J. Li, J. Zhou, Z. Hu, Experimental study of PLLA/INH slow release implant fabricated by three dimensional printing technique and drug release characteristics in vitro, Biomed. Eng. Online. 13 (2014) 1-11. doi:10.1186/1475-925X-13-97.

[29] F. Fina, C.M. Madla, A. Goyanes, J. Zhang, S. Gaisford, A.W. Basit, Fabricating 3D printed orally disintegrating printlets using selective laser sintering, Int. J. Pharm. 541 (2018) 101-107. doi:10.1016/j.ijpharm.2018.02.015.

[30] J. Wang, A. Goyanes, S. Gaisford, A.W. Basit, Stereolithographic (SLA) 3D printing of oral modified-release dosage forms, Int. J. Pharm. 503 (2016) 207-212. doi:10.1016/j.ijpharm.2016.03.016.

[31] M. Kyobula, A. Aderleji, M.R. Alexander, E. Saleh, R. Wildman, I. Ashcroft, P.R. Gellert, C.J. Roberts, 3D inkjet printing of tablets exploiting bespoke complex geometries for controlled and tuneable drug release, J. Control. Release. 261 (2017) 207-215. doi:10.1016/j.jconrel.2017.06.025.

[32] C.A. Schneider, W.S. Rasband, K.W. Eliceiri, NIH Image to ImageJ : 25 years of image analysis, Nat. Methods. 9 (2012) 671-675. doi:10.1038/nmeth.2089.

[33] K.W. Ebagninin, A. Benchabane, K. Bekkour, Rheological characterization of poly(ethylene oxide) solutions of different molecular weights, J. Colloid Interface Sci. 336 (2009) 360-367. doi:10.1016/j.jcis.2009.03.014. 


\section{Journal Pre-proofs}

[34] G. Postiglione, G. Natale, G. Griffini, M. Levi, S. Turri, Conductive 3D microstructures by direct 3D printing of polymer/carbon nanotube nanocomposites via liquid deposition modeling, Compos. Part A Appl. Sci. Manuf. 76 (2015) 110-114. doi:10.1016/j.compositesa.2015.05.014.

[35] B.G. Compton, J.A. Lewis, 3D-printing of lightweight cellular composites, Adv. Mater. 26 (2014) 5930-5935. doi:10.1002/adma.201401804.

[36] M. Faes, H. Valkenaers, F. Vogeler, J. Vleugels, E. Ferraris, Extrusion-based 3D printing of ceramic components, Procedia CIRP. 28 (2015) 76-81 doi:10.1016/j.procir.2015.04.028.

[37] J.H.Y. Chung, S. Naficy, Z. Yue, R.M. Kapsa, A.F. Quigley, S.E. Moulton, G.G.; J. Wallace, G.G. Wallace, Bio-ink properties anc printability for extrusion printing living cells, 2013.

[38] C.C. Chang, E.D. Boland, S.K. Williams, J. B. Hoying, E.M.A. Blvd, Direct-write Bioprintin Three-Dimensonal Biohybrid Systems for Future Regenerative Therapies, J Biomed Mater Res B Appi Biomater. 98 (2013) 160-170. doi:10.1002/jbm.b.31831.Direct-write.

[39] J.R.C. Dizon, A.H. Espera, Q. Chen, R.C. Advincula, Mechanical characterization of 3D-printed polymers, Addit. Manuf. 20 (2018) 44-67. doi:10.1016/J.ADDMA.2017.12.002.

[40] T.C. Okwuosa, D. Stefaniak, B. Arafat, A. Isreb, K.W. Wan, M. Albed Alhnan, Article A Lower Temperature FDM 3D Printing for the Manufacture of Patient - Specific Immediate Release Tablets, Pharm. Res. 33 (2016) 2704-2712.

[41] M. Lille, A. Nurmela, E. Nordlund, S. Metsä-Kortelainen, N. Sozer, Applicability of protein and fiber-rich food materials in extrusion-based 3D printing, J. Food Eng. 220 (2018) 20-27. doi:10.1016/j.jfoodeng.2017.04.034. 
[42] M.M. Crowley, F. Zhang, J.J. Koleng, J.W. McGinity, Stability of polyethylene oxide in matrix tablets prepared by hot-melt extrusion, Biomaterials. 23 (2002) 4241-4248. doi:10.1016/S0142-9612(02)00187-4.

[43] R.W. Warfield, B. Hartmann, Melting and freezing behavior of polyethylene oxide, J. Appl. Phys. 44 (1973) 708-714. doi:10.1063/1.1662248.

[44] T. Yoshihara, H. Tadokoro, S. Murahashi, Normal vibrations of the polymer molecules of helical conformation. IV. Polyethylene oxide and polyethylene-d4oxide, J. Chem. Phys. 41 (1964) 2902-2911. doi:10.1063/1.1726373.

[45] T. Uyar, F. Besenbacher, Electrospinning of cyclodextrin functionalized polyethylene oxide (PEO) nanofibers, Eur. Polym. J. 45 (2009) 1032-1037. doi:10.1016/j.eurpolymj.2008.12.024.

[46] Y.A. Samad, A. Asghar, R. Hashaikeh, Electrospun cellulose / PEO fi ber mats as a solid polymer electrolytes for Li ion batteries, Renew. Energy. 56 (2013) 90-95. doi:10.1016/j.renene.2012.09.015.

[47] F. Wang, C.M. Ma, W. Wu, Thermal degradation of polyethylene oxide blended with novolac type phenolic resin, J. Mater. Sci. 36 (2001) 943-947.

[48] M. Jakic, N. Stipanelov, I. Klaric, Thermal degradation of poly ( vinyl chloride )/ poly ( ethylene oxide) blends : Thermogravimetric analysis, Polym. Degrad. Stab. 98 (2013) 1738-1743. doi:10.1016/j.polymdegradstab.2013.05.024. 


\section{Figure and table legends}

Fig 1. Viscosity of PEO gels $\left(25^{\circ} \mathrm{C}\right)$ intended for $3 \mathrm{D}$ printing. Key: PEO10 $=10 \%$ aqueous PEO gel; PEO15 $=15 \%$ aqueous PEO gel; PEO20 = 20\% aqueous PEO gel.

Fig 2. Photographs of the 3D printed PEO lattices. The three independent variables in the factorial experimental design are given in Table 1. A, B and C denote lattices printed with 10\%, $15 \%$ or $20 \%$ PEO gel accordingly'

Fig 3. Effects of the PEO concentration and printing head speed $(\mathrm{mm} / \mathrm{s})$ on the weight $(\mathrm{mg})(\mathrm{A}$, B) and lattice area $\left(\mathrm{mm}^{2}\right)(\mathrm{C}, \mathrm{D})$ of the 3D printed polymeric lattices $(\mathrm{n}=3)$. A. Surface plot $(\mathrm{A}, \mathrm{C})$ and contour plot $(\mathrm{B}, \mathrm{D})$ presentations. Reference is also made to Table 1.

Fig 4. Effects of the PEO concentration and printing plate temperature $\left({ }^{\circ} \mathrm{C}\right)$ on the lattice area $\left(\mathrm{mm}^{2}\right)$ of the 3D printed polymeric lattices $(\mathrm{n}=3)$. A Surface plot (A) and contour plot $(\mathrm{B})$ presentation. Reference is also made to Table 1.

Fig 5. Effects of the printing head speed $(\mathrm{mm} / \mathrm{s})$ and printing plate temperature $\left({ }^{\circ} \mathrm{C}\right)$ on the lattice area $\left(\mathrm{mm}^{2}\right)$ of the 3D printed polymeric lattices $(\mathrm{n}=3)$. A. Surface plot (A) and contour plot (B) presentation. Reference is also made to Table 1.

Fig 6. Effects of the PEO concentration (A, B), printing head speed (mm/s) (A, C), printing plate temperature $\left({ }^{\circ} \mathrm{C}\right)(\mathrm{B}, \mathrm{C})$ on the lattice area ratio $\left(\mathrm{r}_{\mathrm{x}}\right)$ of the $3 \mathrm{D}$ printed polymeric lattices $(\mathrm{n}=3)$. Reference is also made to Table 1. 
Fig 7. Fourier-transform infrared (FTIR) spectra (A) and X-ray diffraction (XRD) patterns (B) of PEO polymer and 3D printed PEO squares printed on different plate temperatures.

Table 1. Full factorial design matrix $\left(3^{3}\right)$ and the results $(n=3)$. Key: $X 1=$ Concentration of PEO solution: $10 \%(-1), 15 \%(0), 20 \%(+1) ; \mathrm{X} 2$ = Printing head speed (mm/s): $0.5(-1), 1.0$ (0), $1.5(+1) ; \mathrm{X} 3$ = Printing plate temperature $\left({ }^{\circ} \mathrm{C}\right): 30(-1), 50(0), 70(+1)$.

Table 2. The fitted models for unscaled coefficients and responses 


\section{Graphical abstract}

\section{D-printability of aqueous poly(ethylene oxide) gels}


Ivo Laidmäe $e^{a, c}$

${ }^{a}$ Institute of Pharmacy, Faculty of Medicine, University of Tartu, Nooruse 1, 50411 Tartu, Estonia

${ }^{\mathrm{b}}$ Division of Pharmaceutical Chemistry and Technology, Faculty of Pharmacy, Viikinkaari 5E, 00014 University of Helsinki, Finland

${ }^{c}$ Department of Immunology, Institute of Biomedicine and Translational Medicine, Faculty of Medicine, University of Tartu, Ravila 19, 50411 Tartu, Estonia

Model lattices were printed using extrusion-based 3D printing and various process parameters. The present lattices were compared with a theoretical ideal lattice to evaluate the 3Dprintability of aqueous PEO gels.

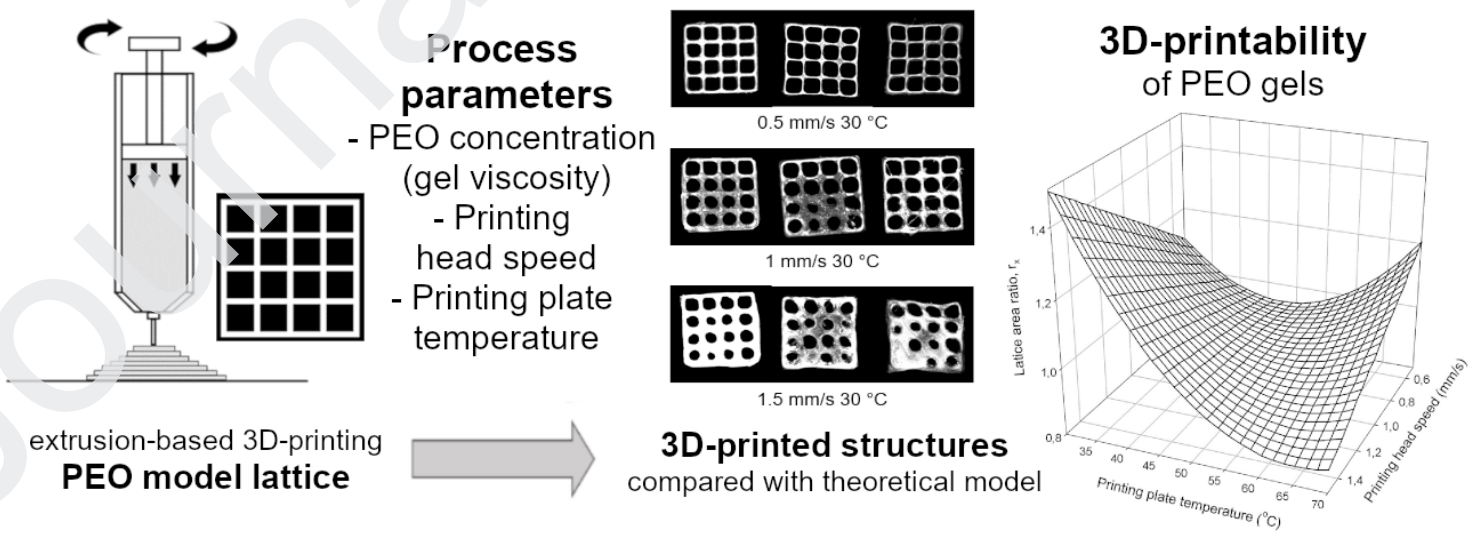




\section{Highlights}

- $\quad \mathrm{PEO}$ is an applicable material for extrusion-based 3D printing

- Printing head speed and plate temperature influence 3D-printability the most

- Extrusion-based printing does not induce solid-state changes in PEO 